\title{
Risk Factors, Prognosis and A New Nomogram for Predicting Cancer-Specific Survival Among Lung Cancer Patients with Brain Metastasis: A Retrospective Study Based on SEER
}

\section{Guihong Zhang ( $\sim$ guihongz@126.com )}

Jiangsu Province Hospital of Chinese Medicine https://orcid.org/0000-0002-4492-1974

Yue Jiao Liu

Jiangsu Province Hospital of Chinese Medicine

Ming De Ji

Jiangsu Province Hospital of Chinese Medicine

\section{Research Article}

Keywords: lung cancer, brain metastasis, risk factors, prognosis, nomogram

Posted Date: June 10th, 2021

DOl: https://doi.org/10.21203/rs.3.rs-591433/v1

License: (c) (1) This work is licensed under a Creative Commons Attribution 4.0 International License. Read Full License

Version of Record: A version of this preprint was published at Lung on January 24th, 2022. See the published version at https://doi.org/10.1007/s00408-021-00503-0. 


\section{Abstract}

Purpose: A comprehensive population-based study on risk and prognostic factors of lung cancer with brain metastasis is lacking.

Methods: 95191 patients diagnosed with lung cancer between 2010 and 2017 were collected from the Surveillance, Epidemiology and End Results (SEER) database. Patients were stratified by different variables. Multivariable logistic and Cox regression were applied to analyze the risk and prognostic factors of brain metastasis among lung cancer patients, respectively. The Fine and Gray's competing risk regression model was performed to obtain prognostic factors associated with cancer-specific mortality.

Results: Among the 95191 patients diagnosed with lung cancer, 10765 patients have brain metastasis, with a metastatic incidence of $11.31 \%$. The primary site of tumor, residence type, age, histological type, race and extracranial metastasis were all independent risk factors of brain metastasis. Compared with other histological types, small cell lung cancer displayed a highest incidence of brain metastasis (16.62\%). The median overall survival (OS) among lung cancer patients with brain metastasis was only 6.05 months. The primary site of tumor, median household income, age, histological type, race, gender and extracranial metastasis were all associated with the prognosis of brain metastasis. Patients with squamous cell carcinoma had the worst prognosis, the median OS was only 3.68 months. And our established new nomogram showed a good discriminative ability on predicting the probability of cancerspecific survival among patients with brain metastasis, the C-index was 0.61 .

Conclusion: Our study provided a deeper insight into the risk factors and prognosis of brain metastasis among lung cancer patients.

\section{Introduction}

Lung cancer is the main contributor of cancer mortality among both men and women in the United States (1). Clinically, most lung cancers eventually develop into advanced diseases with distant metastasis, among which the intracranial metastasis is the most common (2). It has been reported that lung cancer had the higher incidence of brain metastasis compared with other cancers, which also leads to a significantly shorter survival of patients (3). The high morbidity and mortality of intracranial metastasis among lung cancer patients pose a great challenge to clinicians.

At present, the risk and prognostic factors of brain metastasis among lung cancer patients have been analyzed in a large number of studies. Previous articles have shown that elevated serum CEA and NSE levels were positively associated with the risk of brain metastasis among non-small cell lung cancer (NSCLC). In addition, the non-squamous cell carcinoma was more likely to develop brain metastasis compared with other histological type, younger age and the metastasis of lymph node were also the independent risk factors of brain metastasis among $\operatorname{NSCLC}(4,5)$. In order to estimate the prognosis of intracranial metastasis among lung cancer, Sperduto PW et al. updated the graded prognostic assessment of lung cancer with brain metastasis using the molecular markers (Lung-molGPA) (6). In 
addition, a retrospective study investigated the influence of extracranial metastasis on prognosis of NSCLC with intracranial metastasis based on Surveillance, Epidemiology, and End results (SEER) database (7). Although there are many studies on the risk factors and prognosis of brain metastasis among lung cancer patients, these studies mainly focused on NSCLC, or only limited to the impacts of some specific factors on the prognosis of lung cancer patients with brain metastasis. A comprehensive retrospective study on the risk factors and prognosis of brain metastasis among lung cancer patients is lacking.

Our study aimed to investigate the risk and prognostic factors of brain metastasis among lung cancer patients based on the SEER database. Besides, we intended to establish a new practical nomogram, which was suitable for squamous cell carcinoma, adenocarcinoma, adenosquamous carcinoma, neuroendocrine carcinoma and small cell lung cancer (SCLC).

\section{Methods}

\section{Study subjects}

In this study, 140463 lung cancer patients diagnosed between 2010 and 2017 were enrolled as the study population through the SEER database. This database consists of 18 cancer registries from the United States and provides the incidence of cancer, treatment information and follow-up survival data of cancer patients for approximately $30 \%$ of the United States population. Median household income, residence type, age at diagnosis, race and gender were included into the demographic variables, cancer-related variables included primary sites of tumor, histologic types, extracranial metastatic sites to bone and liver, survival time (month) and vital status.

\section{Data collection}

Inclusion criteria for this study were as follows: (a) patients were older than 18 years at the time of diagnosis; (b) histological types were adenocarcinoma, squamous cell carcinomas, adenosquamous carcinoma, neuroendocrine carcinoma and SCLC. the corresponding ID0-0-3 codes were showed in supplementary table 1. The exclusion criteria of this study were as follows: (a) whether there is brain metastasis at the time of diagnosis is not known; (b) the information of demographic variables and cancer-related variables was unknown. We finally identified 95191 lung cancer patients for incidence analysis of brain metastasis, of these, 10765 patients had brain metastasis. Of these patients, we excluded those with incomplete follow-up and those diagnosed by death certificates or autopsy, leaving 8655 patients with brain metastasis for survival analysis.

\section{Statistical methods}

Patients were grouped according to the primary site of tumor, median household income, residence type, age, histological type, race, gender and extracranial metastasis to bone or liver. The number and proportion of patients with brain metastasis from lung cancer were calculated. The incidence of brain 
metastasis among lung cancer patients was obtained by calculating the ratio of the number of lung cancer patients with brain metastases to the total number of lung cancer patients (8).

Multivariable logistic regression was used to analyze whether the primary site of tumor, median household income, residence type, age, histological type, race, gender and extracranial metastatic sites to bone and liver were independent risk factors of brain metastasis among lung cancer patients.

The Kaplan-Meier method was used to obtain the cumulative overall survival curve and median overall survival (OS) time, the difference of survival time among subgroups was compared using the Log-Rank test. The all-cause mortality-related prognostic factors of lung cancer with brain metastasis were identified through multivariable Cox regression analysis using the variables identified in the Log-Rank test.

The Fine and Gray's competing risk regression analysis was applied to investigate the prognostic factors associated with increased cancer-specific mortality. Prognostic nomogram for predicting cancer-specific survival of brain metastasis patients among lung cancer were established based on the independent prognostic factors identified in the Fine and Gray's competing risk regression model (9).

Statistical analysis was completed in the SPSS statistics software (IBM SPSS Statistics, version 21.0) and R software (version 4.0.4.).

\section{Results}

\section{Incidence}

Among the 95191 patients with lung cancer, 10765 patients developed brain metastasis, with a rate of $11.31 \%$. Patients were stratified by the primary site of tumor, median household income, residence type, age, histological type, race, gender and extracranial metastatic sites to bone or liver, the number and proportion of patients with brain metastasis from lung cancer were provided in Table 1 . We found the rate of brain metastasis is highest when the primary site of tumor is main bronchus, up to $14.60 \%$. In addition, younger patients were more likely to develop brain metastasis, the metastatic rate among patients aged 18-41 years and $41-60$ years were $16.22 \%$ and $17.65 \%$, respectively. SCLC and adenocarcinoma had higher rates of brain metastasis ( $16.62 \%$ and $13.37 \%$, respectively) compared with other histological types. The incidence of brain metastasis among Asian population was $14.83 \%$, which was higher than that in other ethnic groups. In addition, when patients had extracranial metastasis to bone and liver, the incidence of brain metastasis was as high as $28.65 \%$.

\section{Table 1. Incidence proportion and median overall survival of lung cancer patients with brain metastasis}




\begin{tabular}{|c|c|c|c|c|}
\hline \multirow[t]{2}{*}{ Variables } & \multicolumn{2}{|l|}{ Patients, No } & \multirow{2}{*}{$\begin{array}{l}\text { Incidence } \\
\text { Proportion of } \\
\text { Brain } \\
\text { Metastasis, \% }\end{array}$} & \multirow{2}{*}{$\begin{array}{l}\text { Median Overall Survival } \\
\text { Among Patients with Brain } \\
\text { Metastasis, } \\
\text { month (IQR) }\end{array}$} \\
\hline & $\begin{array}{l}\text { With Lung } \\
\text { Cancer } \\
(n=95191)\end{array}$ & $\begin{array}{l}\text { With Brain } \\
\text { Metastasis } \\
(n=10765)\end{array}$ & & \\
\hline \multicolumn{5}{|l|}{ Primary site } \\
\hline Upper lobe & 55082 & 6368 & 11.56 & $6.22(2-12)$ \\
\hline Middle lobe & 5072 & 520 & 10.25 & $5.43(2-10)$ \\
\hline Lower lobe & 29861 & 3144 & 10.53 & $6.16(2-12)$ \\
\hline Overlapping & 1046 & 130 & 12.43 & $5.61(1-9)$ \\
\hline Main bronchus & 4130 & 603 & 14.60 & $4.59(1-9)$ \\
\hline $\begin{array}{l}\text { Median } \\
\text { household } \\
\text { income }\end{array}$ & 313 & 34 & 10.86 & NA \\
\hline$<\otimes 35000$ & 20882 & 2391 & 11.45 & $5.17(2-11)$ \\
\hline$\varangle 35000-\rrbracket 54999$ & 43759 & 4742 & 10.84 & $5.55(2-11)$ \\
\hline \55000- $₫ 74999$ & 30237 & 3598 & 11.90 & $7.13(2-13)$ \\
\hline \multicolumn{5}{|l|}{$\triangle 75000+$} \\
\hline \multicolumn{5}{|l|}{ Residence } \\
\hline Urban & 83715 & 9410 & 11.24 & $6.03(2-12)$ \\
\hline Rural & 11476 & 1355 & 11.81 & $6.51(2-11)$ \\
\hline \multicolumn{5}{|l|}{ Age } \\
\hline $18-40$ & 592 & 96 & 16.22 & $15.08(3-19)$ \\
\hline $41-60$ & 18751 & 3310 & 17.65 & $8.52(2-15)$ \\
\hline $61-80$ & 61352 & 6474 & 10.55 & $5.42(1-11)$ \\
\hline$>80$ & 14496 & 885 & 6.11 & $2.86(1-6)$ \\
\hline \multicolumn{5}{|l|}{ Histological type } \\
\hline \multirow{4}{*}{$\begin{array}{l}\text { Squamous cell } \\
\text { carcinomas } \\
\text { Adenocarcinoma } \\
\text { Adenosquamous } \\
\text { carcinoma }\end{array}$} & 25071 & 1282 & 5.11 & $3.68(1-7)$ \\
\hline & 52783 & 7056 & 13.37 & $6.72(2-13)$ \\
\hline & 1196 & 108 & 9.03 & $6.46(2-13)$ \\
\hline & 3514 & 221 & 6.29 & $6.44(1-11)$ \\
\hline $\begin{array}{l}\text { Neuroendocrine } \\
\text { carcinoma }\end{array}$ & 12627 & 2098 & 16.62 & $6.02(1-10)$ \\
\hline
\end{tabular}


Race

$\begin{array}{lllll}\text { White } & 76211 & 8210 & 10.77 & 5.65(2-11) \\ \text { Black } & 10647 & 1345 & 12.63 & 5.93(2-11) \\ \text { Asian } & 7816 & 1159 & 14.83 & 9.39(2-16) \\ \begin{array}{c}\text { American } \\ \text { Indian }\end{array} & 517 & 51 & 9.86 & 6.77(2-12)\end{array}$

Gender

$\begin{array}{lllll}\text { Female } & 47301 & 5342 & 11.29 & 6.73(2-13) \\ \text { Male } & 47890 & 5423 & 11.32 & 5.40(1-10)\end{array}$

Extracranial

metastatic sites

to bone and liver

$\begin{array}{lllll}\text { None } & 74709 & 5963 & 7.98 & 7.48(2-14) \\ \text { Liver } & 11015 & 2536 & 23.02 & 5.37(2-11) \\ \text { Bone } & 4601 & 872 & 18.95 & 3.51(1-7) \\ \text { Liver and Bone } & 4866 & 1394 & 28.65 & 3.81(1-8)\end{array}$

In the multivariable logistic regression model for the incidence analysis of brain metastasis, the primary site: main bronchus (vs upper lobe; odds ratio [OR], 1.12; $95 \% \mathrm{Cl}, 1.01-1.23 ; P=0.024$ ), the residence type: rural (vs urban; OR, $1.10 ; 95 \% \mathrm{Cl}, 1.02-1.18 ; P=0.008$ ), the histological type: adenocarcinoma (vs squamous cell carcinomas; OR, $2.41 ; 95 \% \mathrm{Cl}, 2.27-2.57 ; P<0.001$ ), adenosquamous carcinoma (vs squamous cell carcinomas; $\mathrm{OR}, 1.62 ; 95 \% \mathrm{Cl}, 1.31-1.99 ; P<0.001)$ and small cell lung carcinoma (vs squamous cell carcinomas; OR, 2.48; $95 \% \mathrm{Cl}, 2.29-2.68 ; P<0.001$ ), the race: Black (vs White; OR, 1.13; $95 \% \mathrm{Cl}, 1.06-1.21 ; P<0.001$ ) and Asian (vs White; OR, 1.29; 95\% Cl, 1.20-1.39; $P<0.001$ ), and extracranial metastasis to liver (vs no extracranial metastasis to liver and bone; OR, 3.03; 95\%Cl, 2.87-3.19; $P<0.001$ ), extracranial metastasis to bone (vs no extracranial metastasis to liver and bone; OR, $2.46 ; 95 \% \mathrm{Cl}, 2.26$ $2.67 ; P<0.001)$ and extracranial metastasis to liver and bone (vs no extracranial metastasis to liver and bone; OR, 3.92; $95 \% \mathrm{Cl}, 3.66-4.21 ; P<0.001$ ) were significantly more likely to have brain metastasis at diagnosis. When the primary site of lung cancer was the middle lobe (vs upper lobe; OR, $0.88 ; 95 \% \mathrm{Cl}, 0.80$ $0.97 ; P=0.009$ ) and lower lobe (vs upper lobe; OR, 0.94; OR, 0.90-0.99; $P=0.013$ ), the risk of developing brain metastasis is significantly reduced. Furthermore, patients aged 61-80 (vs aged 18-40; OR, 0.62; $95 \% \mathrm{Cl}, 0.50-0.79 ; P<0.001$ ) and older than 80 (vs aged 18-40; OR, 0.36; 95\% $\mathrm{Cl}, 0.28-0.46 ; P<0.001$ ) were also associated with significantly lower odds of having brain metastasis. The median household income 
and gender were not associated with a risk of brain metastasis. The forest plot makes these results more intuitive (Figure 1).

\section{Survival}

In this study, 7221 deaths (83.43\%) were observed among 8,655 lung cancer patients with brain metastasis, the cumulative overall survival curve showed the median OS among patients with brain metastasis was 6.05 months. Patients were stratified by the primary site of tumor, median household income, residence type, age, histological type, race, gender and extracranial metastatic sites to bone or liver, the median OS of patients with brain metastasis in each subgroup was shown in Table 1. The cumulative overall survival curves were plotted through Kaplan-Meier method and the influence of each factor on prognosis of patients with brain metastasis was identified by Log-Rank test. The results indicated that the primary site, median household income, age, histological type, race, gender and extracranial metastatic sites to bone or liver were all independent prognostic factors of brain metastasis among lung cancer patients (Figure 2).

In the multivariable Cox regression model for the analysis of all-cause mortality of brain metastasis patients among lung cancer, main bronchus (vs upper lobe; hazard ratio [HR], 1.18; 95\% $\mathrm{Cl}, 1.07-1.31$; $P=0.001$ ), age $41-60$ years (vs age $18-40$ years; $\mathrm{HR}, 1.45 ; 95 \% \mathrm{Cl}, 1.10-1.91 ; P=0.009$ ), age $61-80$ years (vs age $18-40$ years; $\mathrm{HR}, 1.91 ; 95 \% \mathrm{Cl}, 1.45-2.51 ; P<0.001)$ and age older than 80 years (vs aged $18-40$ years; $\mathrm{HR}, 3.24 ; 95 \% \mathrm{Cl}, 2.44-4.29 ; P<0.001$ ), male (vs female; $\mathrm{HR}, 1.13 ; 95 \% \mathrm{Cl}, 1.08-1.18, P<0.001$ ) and extracranial metastasis to liver (vs no extracranial metastasis to liver and bone; $\mathrm{HR}, 1.34 ; 95 \% \mathrm{Cl}, 1.26$ 1.42; $P<0.001$ ), extracranial metastasis to bone (vs no extracranial metastasis to liver and bone; $\mathrm{HR}, 1.80$; $95 \% \mathrm{Cl}, 1.65-1.96 ; P<0.001)$ and extracranial metastasis to liver and bone (vs no extracranial metastasis to liver and bone; $\mathrm{HR}, 1.75 ; 95 \% \mathrm{Cl}, 1.63-1.87 ; P<0.001)$ were significantly associated with a higher allcause mortality. In addition, $₫ 55000-\varangle 74999$ (vs $₫ 35000-\varangle 54999 ; \mathrm{HR}, 0.90 ; 95 \% \mathrm{Cl}, 0.84-0.97 ; P=0.004$ )

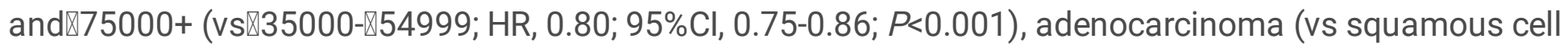
carcinomas; HR, $0.66 ; 95 \% \mathrm{Cl}, 0.61-0.71 ; P<0.001$ ), adenosquamous carcinoma (vs squamous cell carcinomas; HR, 0.78; 95\% Cl, 0.61-0.98; $P<0.001$ ), neuroendocrine carcinoma (vs squamous cell carcinomas; $\mathrm{HR}, 0.69 ; 95 \% \mathrm{Cl}, 0.58-0.82 ; P<0.001$ ) and small cell lung carcinoma (vs squamous cell carcinomas; HR, $0.80 ; 95 \% \mathrm{Cl}, 0.74-0.88 ; P<0.001$ ) and Asian (vs White; HR, 0.77; 95\% Cl, 0.71-0.83; $P<0.001)$ were associated with a lower all-cause mortality. The results were showed in Table 2.

Table 2 Multivariable Cox regression for all-cause mortality and cancer-specific mortality among patients with brain metastasis 


\begin{tabular}{|c|c|c|c|c|c|}
\hline \multirow[t]{2}{*}{ Variables } & \multirow[t]{2}{*}{$\begin{array}{l}\text { Patients with brain } \\
\text { metastasis }(n=8255)\end{array}$} & \multicolumn{2}{|c|}{ All-Cause Mortality } & \multicolumn{2}{|c|}{$\begin{array}{l}\text { Cancer-Specific } \\
\text { Mortality }\end{array}$} \\
\hline & & $\begin{array}{l}\text { Hazard Ratio } \\
(95 \mathrm{Cl} \%)\end{array}$ & $\begin{array}{l}P \\
\text { value }\end{array}$ & $\begin{array}{l}\text { Hazard } \\
\text { Ratio } \\
\text { (95Cl\%) }\end{array}$ & $\begin{array}{l}P \\
\text { value }\end{array}$ \\
\hline \multicolumn{6}{|l|}{ Primary site } \\
\hline Upper lobe & 5123 & Reference & NA & Reference & NA \\
\hline Middle lobe & 418 & $\begin{array}{l}1.10(0.99- \\
1.23)\end{array}$ & 0.078 & $\begin{array}{l}1.03(0.92- \\
1.16)\end{array}$ & 0.620 \\
\hline Lower lobe & 2544 & & 0.490 & & 0.110 \\
\hline Overlapping & 98 & $\begin{array}{l}0.98\left(0.93^{-}\right. \\
1.03)\end{array}$ & 0.316 & $\begin{array}{l}0.96(0.91- \\
1.01)\end{array}$ & 0.880 \\
\hline \multirow[t]{2}{*}{ Main bronchus } & 472 & $\begin{array}{l}1.12(0.90- \\
1.39)\end{array}$ & 0.001 & $\begin{array}{l}1.02(0.81- \\
1.28)\end{array}$ & 0.022 \\
\hline & & $\begin{array}{l}1.18(1.07- \\
1.31)^{(10}\end{array}$ & & $\begin{array}{l}1.14(1.02- \\
1.26)\end{array}$ & \\
\hline \multicolumn{6}{|l|}{$\begin{array}{l}\text { Median household } \\
\text { income }\end{array}$} \\
\hline$\bigotimes 35000-\varangle 54999$ & 1328 & Reference & NA & & \\
\hline ه55000- $₫ 74999$ & 3811 & $\begin{array}{l}0.90(0.84- \\
0.97)\end{array}$ & & $\begin{array}{l}0.93(0.87- \\
1.00)\end{array}$ & \\
\hline & 3516 & $\begin{array}{l}0.80(0.75- \\
0.86)\end{array}$ & $<0.001$ & $\begin{array}{l}0.85(0.79- \\
0.91)\end{array}$ & $<0.001$ \\
\hline \multicolumn{6}{|l|}{ Age } \\
\hline $18-40$ & 80 & Reference & NA & & NA \\
\hline $41-60$ & 2649 & $1.45(1.10-$ & 0.009 & $\begin{array}{l}1.41(1.11- \\
179)\end{array}$ & 0.005 \\
\hline $61-80$ & 5181 & & $<0.001$ & & $<0.001$ \\
\hline \multirow[t]{2}{*}{$>80$} & 745 & $2.51)$ & $<0.001$ & $\begin{array}{l}1.6 /(1.32- \\
2.11)\end{array}$ & $<0.001$ \\
\hline & & $\begin{array}{l}3.24(2.44- \\
4.29)\end{array}$ & & $\begin{array}{l}2.40(1.87- \\
3.08)\end{array}$ & \\
\hline \multicolumn{6}{|l|}{ Histological type } \\
\hline Squamous cell & 970 & Reference & NA & & NA \\
\hline Adenocarcinoma & 5770 & $\begin{array}{l}0.66(0.61- \\
0.71)\end{array}$ & $<0.001$ & $\begin{array}{l}0.74(0.68- \\
0.80)\end{array}$ & $<0.001$ \\
\hline Adonoganmou & 88 & 1067 & 0.033 & & 0.350 \\
\hline $\begin{array}{l}\text { Adenosquamous } \\
\text { carcinoma }\end{array}$ & 179 & $\begin{array}{l}0 . / 8(0.61- \\
0.98)\end{array}$ & $<0.001$ & $\begin{array}{l}0.91\left(0 . / 4^{-}\right. \\
1.12)\end{array}$ & 0.002 \\
\hline $\begin{array}{l}\text { Neuroendocrine } \\
\text { carcinoma }\end{array}$ & 1648 & $\begin{array}{l}0.69(0.58- \\
0.82)\end{array}$ & $<0.001$ & $\begin{array}{l}0.75(0.62- \\
0.90)\end{array}$ & 0.019 \\
\hline
\end{tabular}




\begin{tabular}{|c|c|c|c|c|c|}
\hline \multicolumn{2}{|l|}{$\begin{array}{l}\text { Small cell lung } \\
\text { carcinoma }\end{array}$} & \multicolumn{2}{|l|}{$\begin{array}{l}0.80(0.74- \\
0.88)\end{array}$} & \multicolumn{2}{|l|}{$\begin{array}{l}0.90(0.82- \\
0.98)\end{array}$} \\
\hline \multicolumn{6}{|l|}{ Race } \\
\hline White & 6209 & Reference & NA & NA & NA \\
\hline Black & 1292 & $\begin{array}{l}0.98(0.91- \\
1.05)\end{array}$ & 0.512 & $\begin{array}{l}0.93(0.87- \\
1.00)\end{array}$ & 0.040 \\
\hline Asian & 1112 & & $<0.001$ & & $<0.001$ \\
\hline \multirow{2}{*}{ American Indian } & 42 & $0.83)$ & 0.626 & $0.89)$ & 0.990 \\
\hline & & $\begin{array}{l}1.08(0.78- \\
1.50)\end{array}$ & & $\begin{array}{l}1.00(0.74- \\
1.36)\end{array}$ & \\
\hline \multicolumn{6}{|l|}{ Gender } \\
\hline Female & 4352 & Reference & NA & NA & NA \\
\hline Male & 4303 & $\begin{array}{l}1.13(1.08- \\
1.18)\end{array}$ & $<0.001$ & $\begin{array}{l}1.11(1.06- \\
1.16)\end{array}$ & $<0.001$ \\
\hline \multicolumn{6}{|l|}{$\begin{array}{l}\text { Extracranial } \\
\text { metastatic sites }\end{array}$} \\
\hline \multicolumn{5}{|l|}{ to bone and liver } & NA \\
\hline \multirow{2}{*}{ Liver } & 2085 & $\begin{array}{l}1.34(1.26- \\
1.42)\end{array}$ & $<0.001$ & $\begin{array}{l}1.30(1.23- \\
138)\end{array}$ & $<0.001$ \\
\hline & 708 & & $<0.001$ & & $<0.001$ \\
\hline \multirow{2}{*}{$\begin{array}{l}\text { Bone } \\
\text { Liver and Bone }\end{array}$} & 1096 & $\begin{array}{l}1.80(1.65- \\
1.96)\end{array}$ & $<0.001$ & $\begin{array}{l}1.60(1.4 /- \\
1.75)\end{array}$ & $<0.001$ \\
\hline & & $\begin{array}{l}1.75(1.63- \\
1.87)\end{array}$ & & $\begin{array}{l}1.59(1.48- \\
1.71)\end{array}$ & \\
\hline
\end{tabular}

In the Fine and Gray's competing risk regression model for the analysis of cancer-specific mortality of brain metastasis patients among lung cancer, $₫ 55000-\varangle 74999$ (vs $₫ 35000-\varangle 54999 ; \mathrm{HR}, 0.93 ; 95 \% \mathrm{Cl}, 0.87$ $1.00 ; P=0.056$ ) and adenosquamous carcinoma (vs squamous cell carcinomas; $\mathrm{HR}, 0.91 ; 95 \% \mathrm{Cl}, 0.74$ $1.12 ; P=0.350$ ) were not significantly associated with a lower cancer-specific mortality. The results were also showed in Table 2. Based on the results of Fine and Gray's competing risk regression, we developed a novel visual nomogram to predict the cancer-specific survival of lung cancer patients with brain metastasis, showed in Figure 3. A patient's cancer-specific survival probability can be easily estimated by calculating the scores for each variable. Through internal validation by Heagerty's concordance index, the established nomogram showed a good discriminative ability, the C-index was 0.61 .

\section{Discussion}

The highlights of our work mainly include three aspects. First, we comprehensively analyzed the incidence and risk factors of brain metastasis among patients with lung cancer based on a population- 
based study, and a large number of variables were incorporated. Next, we identified a large number of prognostic factors that influence overall survival and cancer-specific survival of brain metastasis patients among lung cancer based on the multivariable Cox regression and Fine and Gray's competing risk regression analysis. Furthermore, we developed a new practical nomogram for predicting the probability of cancer-specific survival among lung cancer patients with brain metastasis, which was suitable for squamous cell carcinoma, adenocarcinoma, adenosquamous carcinoma, neuroendocrine carcinoma and SCLC.

The high incidence of brain metastasis from lung cancer is a serious threat to lung cancer patients and imposes a great challenge on clinicians. Prophylactic cranial irradiation (PCI) is proposed in both SCLC and non-small-cell lung cancer (NSCLC) in order to improve the survival and quality of life of lung cancer patients with brain metastasis (10). However, many patients refused to undergo PCl in clinical practice because of concerns about the neurotoxicity of craniocerebral irradiation. Identifying lung cancer patients at a high risk of brain metastasis may enhance the benefits of $\mathrm{PCl}$ while decreasing the risks of unnecessary craniocerebral irradiation among the patients with lung cancer. Previous studies on the incidence and risk factors of brain metastasis among lung cancer patients mainly focused on the NSCLC, and the clinical implications are limited. In our study, we comprehensively analyzed the risk factors related to the high incidence of brain metastasis among patients with lung cancer based on the SEER database, including SCLC and NSCLC patients.

Recent years, many researches have indicated that patients with non-squamous cell carcinoma or adenocarcinoma had a higher incidence of brain metastasis $(4,11,12)$, which is consistent with our results in this study. Our study revealed that SCLC is more easily to have brain metastasis than other histologic types of lung cancer, with a rate of $16.62 \%$, followed by adenocarcinoma with a rate of $13.37 \%$; and squamous cell carcinomas and neuroendocrine carcinoma had a lower rates of brain metastasis, the rate was $5.11 \%$ and $6.29 \%$, respectively. Furthermore, we found that lung cancer with a primary site of main bronchus was more likely to have brain metastasis, in addition, the rates of brain metastasis were higher among Asian and Black populations than White populations. The value of gender to predict the rate of brain metastasis among patients with lung cancer is still controversial $(13,14)$, our results showed that gender were not significantly correlated with the risk of brain metastasis. Many studies have indicated that patients with younger age were more easily to have brain metastasis among NSCLC (15, 16), our findings also suggested that younger age is an independent risk factor of brain metastasis among lung cancer patients. It is also worth noting that extracranial metastasis is also an independent risk factor of brain metastasis among lung cancer patients, when patients presented with liver or bone metastasis, the risk of brain metastasis was significantly increased, and the risk of brain metastasis is highest when patients had both liver and bone metastasis.

The research on the prognosis of brain metastasis patients among lung cancer could provide guidance for clinicians in the treatment and management of patients with lung cancer. Previous epidemiological researches have shown that patients with brain metastasis among lung cancer had a very short survival time $(7,17)$, and our study also showed a high mortality among patients with brain metastasis from lung 
cancer. We found the 1-year overall survival rate was only $28 \%$ among patients with brain metastasis, and the median OS time of these patients is 6.05 months, consistent with the results of other studies (18). In the multivariable Cox regression model for the analysis of all-cause mortality of lung cancer patients with brain metastasis, patients with older age and lower income had a higher all-cause mortality. Besides, female and Asian population had a significantly lower all-cause mortality compared with male and White population. And when patients had extracranial metastasis to bone, patients had a worst prognosis, the median OS time was only 3.51 months. Interestingly, we also found that although the brain metastasis rates of lung cancer patients with squamous cell carcinoma was low, the prognosis was very poor once the squamous cell carcinoma developed brain metastasis, with a median OS time of only 3.68 months, which is significantly shorter than other histological types of lung cancer. This may be related to the insensitivity of squamous cell carcinoma to radiotherapy and chemotherapy.

\section{Conclusion}

Our study provided a deeper insight into the risk factors and prognosis of brain metastasis among lung cancer patients. And we developed a new practical nomogram, which was suitable for squamous cell carcinoma, adenocarcinoma, adenosquamous carcinoma, neuroendocrine carcinoma and SCLC, and it greatly expands the scope of clinical applications of nomogram for predicting cancer-specific survival of patients with brain metastasis from lung cancer.

\section{Declarations}

Funding: This work was funded by the National Natural Science Foundation of China (Grant Number: 81603358), which is led by Ji Mingde.

Conflicts of interest: The authors have declared that no competing interests exist.

Availability of data and material: Data in this study are public in the Surveillance, Epidemiology, and End Results (SEER) database (https://seer.cancer. gov/data/).

Code availability: Not applicable.

Authors' contributions: The acquisition and analysis of data was completed by Zhang Guihong, the writing of the manuscript was completed by Zhang Guihong and Liu Yuejiao. The design and guidance of this study was performed by JI Mingde.

Ethics approval: Not applicable.

Consent to participate: Not applicable.

Consent for publication: Written informed consent for publication was obtained from all participants.

\section{References}


1. Siegel RL, Miller KD, Jemal A (2020) Cancer statistics, 2020. CA Cancer J Clin 70(1):7-30

2. Wang X, Adjei AA (2015) Lung cancer and metastasis: new opportunities and challenges. Cancer Metastasis Rev 34(2):169-171

3. Goldberg SB, Contessa JN, Omay SB, Chiang V (2015) Lung Cancer Brain Metastases. Cancer J 21(5):398-403

4. Ji Z, Bi N, Wang J, Hui Z, Xiao Z, Feng Q et al (2014) Risk factors for brain metastases in locally advanced non-small cell lung cancer with definitive chest radiation. Int J Radiat Oncol Biol Phys 89(2):330-337

5. An N, Jing W, Wang H, Li J, Liu Y, Yu J et al (2018) Risk factors for brain metastases in patients with non-small-cell lung cancer. Cancer Med 7(12):6357-6364

6. Sperduto PW, Yang TJ, Beal K, Pan H, Brown PD, Bangdiwala A et al (2017) Estimating Survival in Patients With Lung Cancer and Brain Metastases: An Update of the Graded Prognostic Assessment for Lung Cancer Using Molecular Markers (Lung-molGPA). JAMA Oncol 3(6):827-831

7. Wang M, Wu Q, Zhang J, Qin G, Yang T, Liu Y et al (2021) Prognostic impacts of extracranial metastasis on non-small cell lung cancer with brain metastasis: A retrospective study based on surveillance, epidemiology, and end results database. Cancer Med 10(2):471-482

8. Martin AM, Cagney DN, Catalano PJ, Warren LE, Bellon JR, Punglia RS et al (2017) Brain Metastases in Newly Diagnosed Breast Cancer: A Population-Based Study. JAMA Oncol 3(8):1069-1077

9. Ruiz-Cerda JL, Soto-Poveda A, Lujan-Marco S, Loras-Monfort A, Trassierra-Villa M, Rogel-Berto R et al (2017) Competing risk analysis of mortality in prostate cancer treated with radical prostatectomy. Actas Urol Esp 41(1):11-22

10. Pugh TJ, Gaspar LE (2007) Prophylactic cranial irradiation for patients with lung cancer. Clin Lung Cancer 8(6):365-368

11. Kilickap S, Aksoy S, Erman M (2005) Multivariate analysis of factors predictive of brain metastases in localised non-small call lung carcinoma. Lung Cancer 49(1):129; author reply 31

12. Robnett TJ, Machtay M, Stevenson JP, Algazy KM, Hahn SM (2001) Factors affecting the risk of brain metastases after definitive chemoradiation for locally advanced non-small-cell lung carcinoma. $J$ Clin Oncol 19(5):1344-1349

13. Sun DS, Hu LK, Cai Y, Li XM, Ye L, Hou HY et al (2014) A systematic review of risk factors for brain metastases and value of prophylactic cranial irradiation in non-small cell lung cancer. Asian Pac $\mathrm{J}$ Cancer Prev 15(3):1233-1239

14. Jacot W, Quantin X, Boher JM, Andre F, Moreau L, Gainet M et al (2001) Brain metastases at the time of presentation of non-small cell lung cancer: a multi-centric AERIO analysis of prognostic factors. $\mathrm{Br}$ J Cancer 84(7):903-909

15. Ceresoli GL, Reni M, Chiesa G, Carretta A, Schipani S, Passoni P et al (2002) Brain metastases in locally advanced nonsmall cell lung carcinoma after multimodality treatment: risk factors analysis. Cancer 95(3):605-612 
16. Schouten LJ, Rutten J, Huveneers HA, Twijnstra A (2002) Incidence of brain metastases in a cohort of patients with carcinoma of the breast, colon, kidney, and lung and melanoma. Cancer 94(10):2698-2705

17. Ali A, Goffin JR, Arnold A, Ellis PM (2013) Survival of patients with non-small-cell lung cancer after a diagnosis of brain metastases. Curr Oncol 20(4):e300-e306

18. Cagney DN, Martin AM, Catalano PJ, Redig AJ, Lin NU, Lee EQ et al (2017) Incidence and prognosis of patients with brain metastases at diagnosis of systemic malignancy: a population-based study. Neuro Oncol 19(11):1511-1521

\section{Figures}

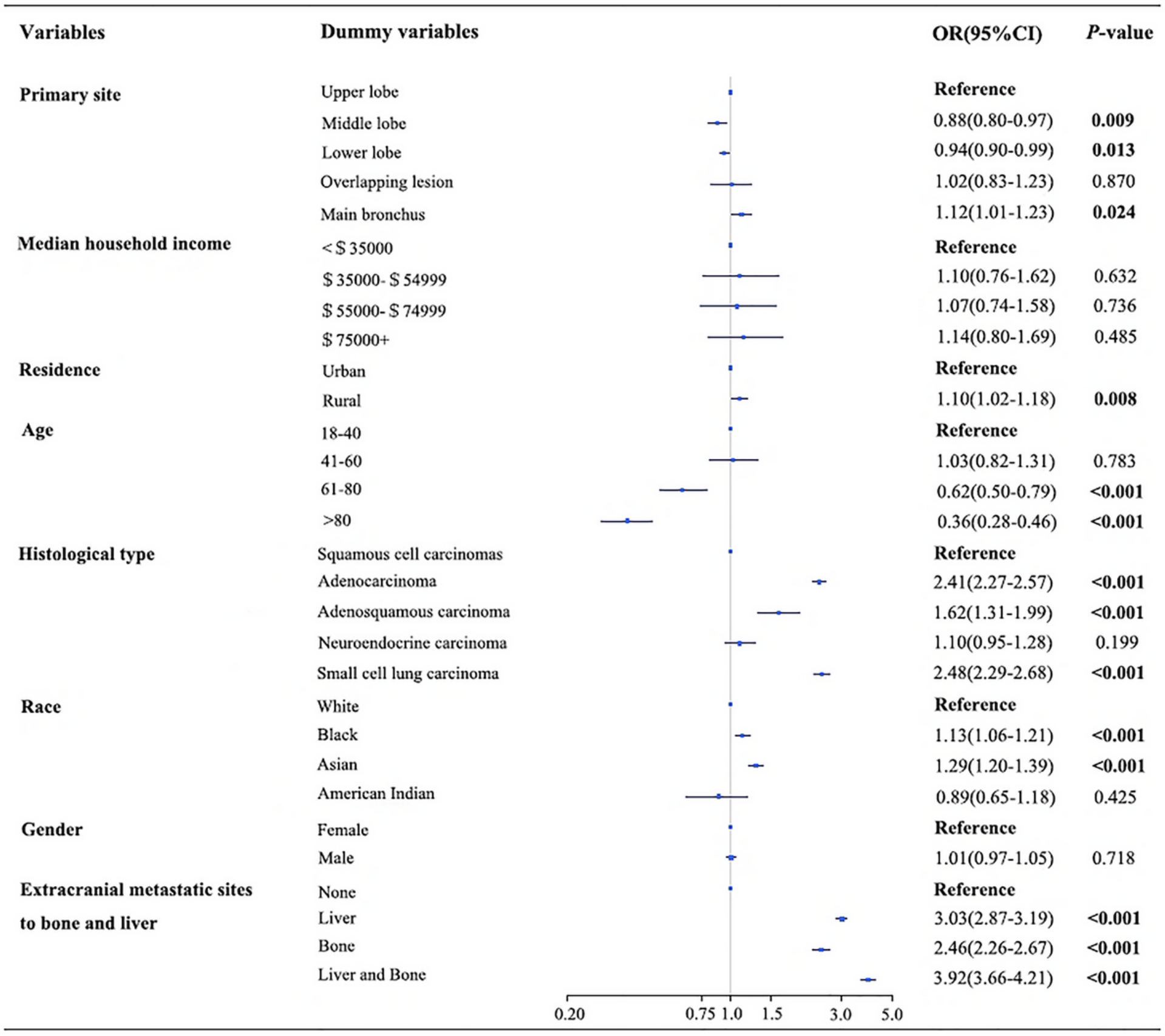


Figure 1

Forest plot visualizing the influence of different factors on the risk of brain metastasis based on multivariable logistic regression.
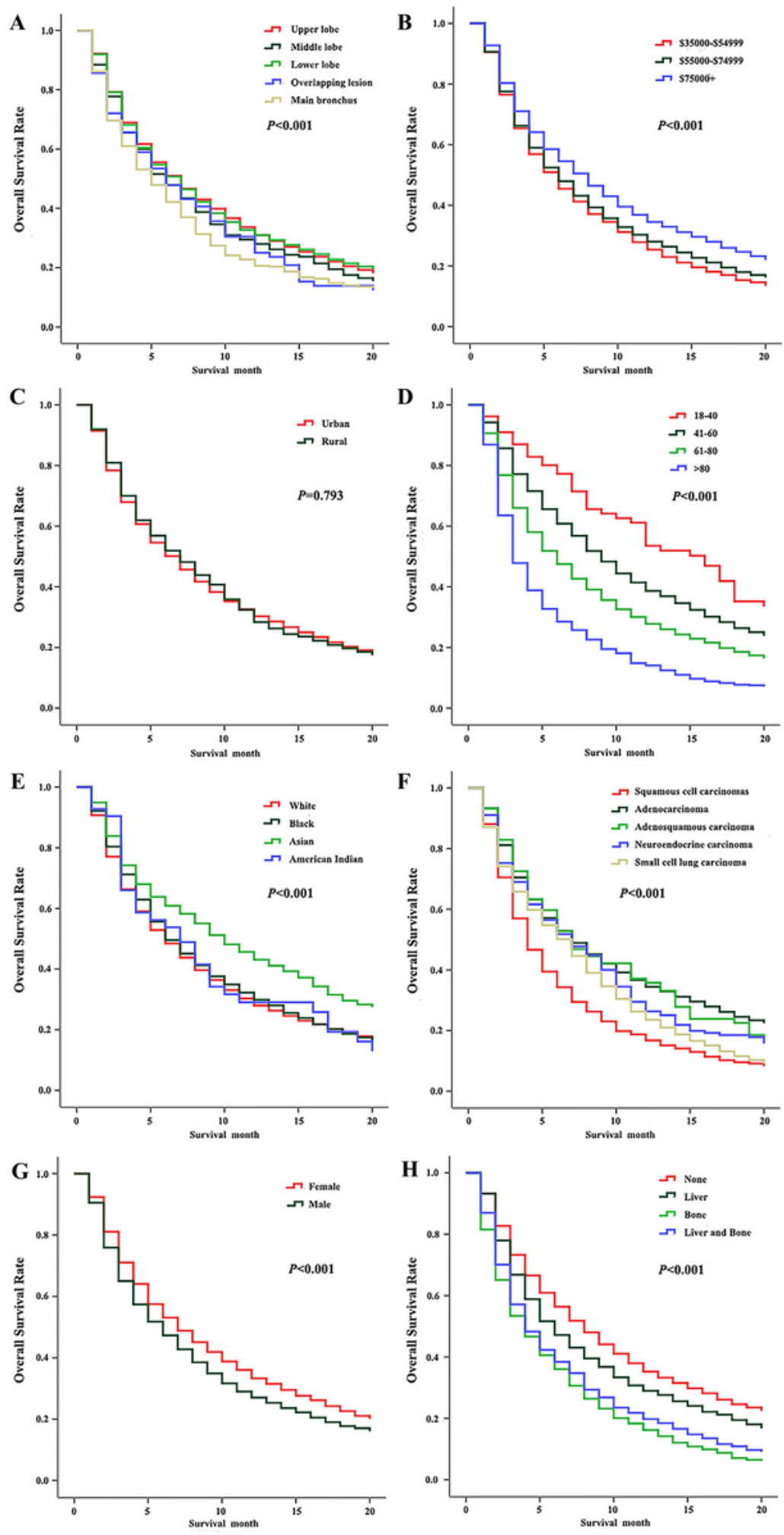

Figure 2 
Overall survival curves grouped by patient characteristics: (A) Primary site; (B) Median household income; (C) Residence; (D) Age; (E) Race; (F) Histological type; (G) Gender; (H) Extracranial metastatic sites to bone and liver.

Points

$\mathbf{0}$

20

40

60

80

100

Primary site

Median household income

Age

Histological type

Race

Gender

Extracranial metastatic sites to bone and liver
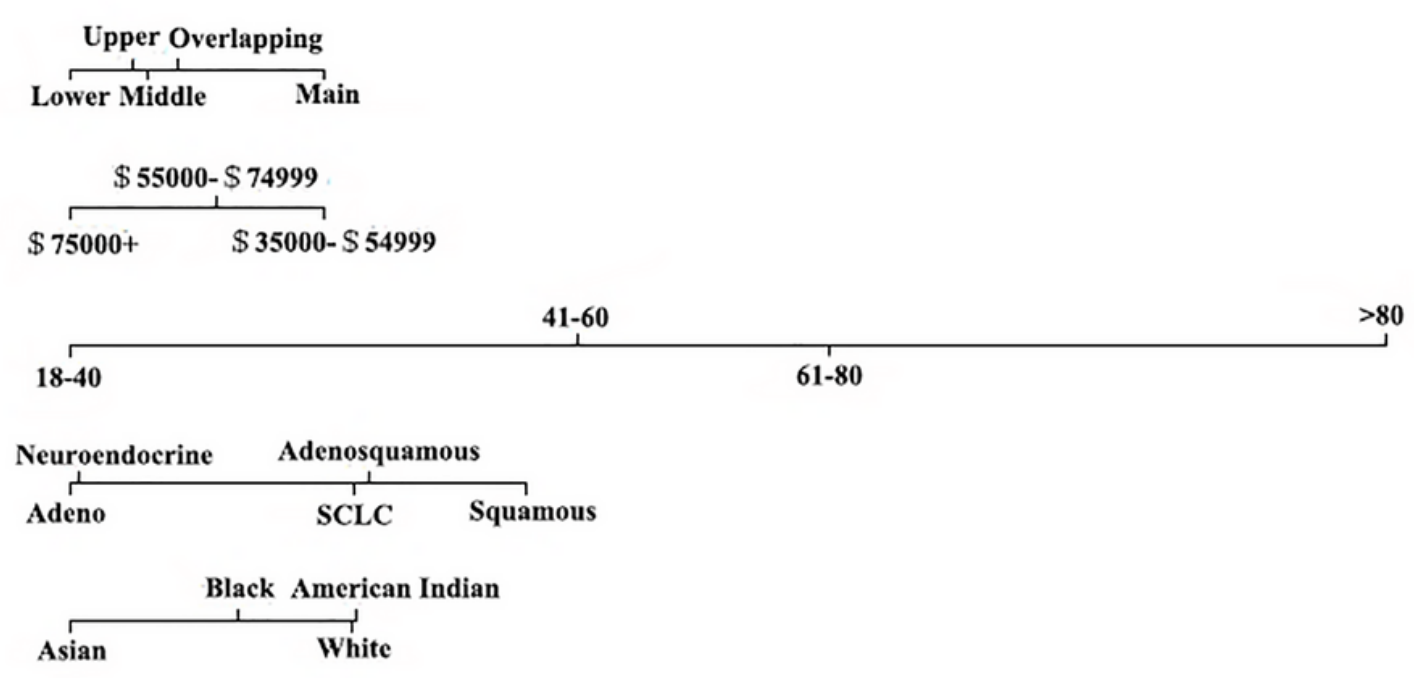

Male

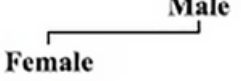

Total Points

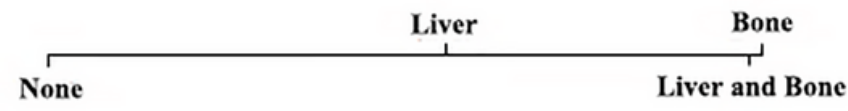

3-month CSS Probability

\begin{tabular}{lllllll}
\hline 0.8 & \multicolumn{1}{c}{} & & & & \\
& 0.7 & 0.6 & 0.5 & 0.4 & 0.3 & 0.2
\end{tabular}

6-month CSS Probability

\begin{tabular}{lllllllllll}
\hline & 0 & 40 & 80 & 120 & 160 & 200 & 240 & 280
\end{tabular}

\section{Figure 3}

A new Nomogram for predicting cancer-specific survival of brain metastasis patients among lung cancer

\section{Supplementary Files}

This is a list of supplementary files associated with this preprint. Click to download.

- SupplementaryTable1.docx 